Turmoil in the world financial markets has forced big government spending to relieve the crisis—but at what cost?

Tarcon he unprecedented recent turmoil in the world financial markets is hard to comprehend from many angles, not least of which is the amount of money lost or proposed as being needed to ameliorate the crisis. The US government has now committed over $\$ 700$ billion to ease the financial crisis. Among other effects, this is likely to have consequences on the US government's capacity to fund 'business as usual' in the years ahead.

Even before the US Congress passed the bailout bill, worries about the financial ability of the US government were realized in a US Senate vote to freeze all government spending except for defense and security purposes. But now the $\$ 700$ billon bailout is law —and follows on the heels of $\$ 85$ billion to support the beleaguered insurance company AIG and $\$ 200$ billion for the mortgage companies Fannie Mae and Freddie Mac, which together will raise the US debt ceiling to approximately $\$ 11.3$ trillion. Remarkably, it is not even clear if the $\$ 700$ billon amount will be enough to fix the underlying problem as the financial crisis spreads globally. The ultimate cost to the US and other governments is also not clear.

To put the scale of the possible financial market bailout into perspective, $\$ 700$ billion is roughly 3.4 times the 2008 budget of the European
Union. Perhaps closer to home for readers of Nature Immunology, $\$ 700$ billion dollars is 24 times the 2008 budget of the entire National Institutes of Health (NIH).

Closely watched in the biomedical community is the annual budget of the NIH. The 2009 budget proposed by the Bush administration was already set to stall biomedical research with its zero increase. But now that the US government and taxpayers will be burdened with the consequences of the financial market debacle, hope that a new administration will have the means to substantially increase NIH funding may fade.

Even before the present financial crisis, ineffective political lobbying and disengagement of the public on the importance of biomedical research may have contributed to the present state of anemic science funding. Now that combination may join forces with a debt of at least $\$ 11.3$ trillion to form what could become a prolonged stalemate for government-supported biomedical research.

We suggest that the biomedical research community take a proactive stance against this problem: those who have the ability and knowledge to influence politicians and the public to invest in scientific research must make every effort to be heard loud and clear to ensure the continued advance of the present amount of scientific research, at the very least.

\title{
Fostering hope and wonder
}

\section{The Large Hadron Collider exemplifies big, bold science that can bring great breakthroughs and, perhaps equally importantly, inspire the public's sense of purpose and possibility.}

$$
\text { T }
$$
he much anticipated powering-up of the Large Hadron Collider (LHC) has certainly captured the imagination of people the world over. Built in an existing 27-kilometer circular tunnel on the FrancoSwiss border at a cost of approximately US $\$ 5$ billion, the LHC was designed to smash protons together to solve some of the basic mysteries of the universe. It is not difficult to see how such an exotic goal-no doubt the envy of scientists in other fields — can foster wonder about science in the public's imagination. Aside from the obvious financial constraints, what are some of the basic issues physicists had to overcome before building the LHC?

An obvious one is agreement among scientists on an appropriate goal. The LHC has been the aim of a considerable portion of the physics community for three decades, with hundreds of scientists agreeing that it was necessary. This seems simple enough, yet few might argue that similar collective agreement about what 'needs to be done' forms less frequently in other scientific fields—such as in biological research. Why?

One possibility is that the fundamental questions to be addressed-on par with solving basic mysteries of the universe - may not in fact be as well defined in other fields as they apparently are in physics, so it is not hard to see the difficulty of other researchers' taking a collective step in one direction. This may be especially true in the biological sciences, in which people undertake solving 'their own' scientific questions and independent efforts do not easily align into a single 'big picture' that provides a definitive conclusion on what to do next-although occasionally they do, as when the human genome was sequenced.

Perhaps even more important for an 'LHC-like' project is that the scientists involved must transcend the singular goals of individual advancement, reward and acknowledgment for discovery. Biologists in particular seem to be solitary creatures who, by dint of professional expectation ('you must have $\mathrm{X}$ number of first-author papers to get an interview or a job here!'), often shy away from collective work and sharing the spotlight.

Such obstacles, which hopefully can be overcome, stand in the way of the potential payback of projects on the scale of the LHC, including discoveries that would have been impossible otherwise, and fostering more study of science. 